\title{
Driving retirement program for seniors: long overdue
}

Previously published at www.cmaj.ca

A s a society, when we weigh public safety against personal choice, public safety wins - and so it should. Yet many people seem to be able to turn a blind eye to public safety when it comes to elderly seniors who shouldn't drive.

The point is not to get seniors - who are, for the most part, our safest drivers - off the roads. However, the ability to drive safely decreases with age, because of the growing list of medical conditions that can affect fitness to drive. ${ }^{1}$ For people over 65 years of age, the crash rate per kilometre travelled increases until, by age 75 , it surpasses that for teenage drivers. ${ }^{2} \mathrm{We}$ are living longer, and the proportion of drivers over 65 is increasing rapidly; by 2025, one in four Canadians will be 65 years of age or older.

Just as planning for job retirement is the social norm, we should be planning for driving retirement by creating programs to help seniors drive safely for as long as possible and, when they can't, to help them get around.

In Canada, as in other industrialized countries, physicians are often required to be the licensing gatekeepers. Office assessments are based on documentation of visual, cognitive or other health problems that may impair driving. However, determining when a condition is debilitating enough to preclude safe driving is extremely difficult. Physicians have no objective assessment tool to help them determine whether a senior is able to drive safely. A simple, widely applicable screening assessment tool is sorely needed.

In the interim, we have to deal with this growing problem and its repercussions. Our urban environment generally centres on the car for transportation. In suburban and rural settings, where many seniors live, public transit is often limited, and taxis are expensive or nonexistent. Not being able to drive may lead to social isolation, a loss of independence and even a deterioration in health.

How can the interests of ensuring that only the competent are permitted to drive be balanced against the need to maintain health and well-being?

A cut-off age for licences is neither sensible nor appropriate, because seniors are so heterogeneous with respect to health and cognition. Clearly, physicians and other health professionals will always be required to report people whom they suspect are unsafe drivers. However, only governments, using standardized driving assessments, should be responsible for revoking a driver's licence.

Physicians and families need to be honest with seniors about the need to retire from driving, and seniors need to accept that, no matter how good the support system, their lives will subsequently not be as flexible.
The reverse graduated licence used in some jurisdictions should be adopted by all provinces. Such conditional licences could, for example, limit driving at night, when vision may be poorer, and restrict access to four-lane highways, rush-hour traffic times or distance travelled.

Social and health care institutions should establish peer counselling programs to make the transition to driving retirement easier; they could consider restricted driving when scheduling appointments and events, giving priority to the needs of seniors rather than the convenience of health care providers.

We also need a national dialogue about how to support seniors in their communities as they retire from driving. Municipalities, health care authorities, community groups and charities and all levels of governments can develop creative solutions for driving retirees. For example:

- Tax or financial incentives could be offered when people carpool to grocery stores and social events.

- Urban planners could be mandated to take seniors' needs into account when considering availability of public transit, and placement of housing and shopping areas.

- Subsidized shuttle van services could be developed in suburban and rural communities.

- Local businesses and community organizations could establish programs such as the grocery bus model, where school buses are used in off-hours on specific days to pick up seniors, take them to the store for shopping and a coffee break, and return them home.

Without such programs, our seniors may find themselves in nursing homes prematurely, at significant personal and public expense.

Solutions to the dilemma of who will drive our seniors and eventually us - must be found. The status quo leaves too many seniors isolated and puts too many people at risk.

\section{Noni MacDonald MD MHSc}

Section Editor, Public Health, CMAJ

Paul C. Hébert MD MHSc

Editor-in-Chief, CMAJ

With the editorial advisory team: Ken Flegel MDCM MSc, Matthew B. Stanbrook MD PhD and Joan Ramsay BA

Competing interests: See www.cmaj.ca/misc/edboard.shtml

CMAJ 2010. DOI:10.1503/cmaj.100273

\section{REFERENCES}

1. Butcher DJM. Fitness to drive. CMAJ 2006;175:575-6.

2. Langford J, Methorst R, Hakamies-Blomqvist L. Older drivers do not have a high crash risk - a replication of low mileage bias. Accid Anal Prev 2006;38:574-8. 